\title{
Cólera, Iglesia católica y gobierno civil en Chiapas, 1833-1835
}

\section{Cholera, the Catholic Church and Civic Government in Chiapas State, 1833-1835}

\author{
José Javier Guillén Villafuerte \\ Facultad de Filosofía y Letras de la Benemérita Universidad Autónoma de Puebla \\ jjgvillafuerte@hotmail.com \\ ORCID:orcid.org/0000-0002-3343-6623
}

Resumen:

En 1833, la república mexicana padeció el embate de la primera epidemia de cólera morbo de su historia. Este artículo estudia las medidas que adoptaron las autoridades civiles y religiosas de Chiapas para proteger de ese mal a los habitantes de la región. Asimismo, se busca mostrar cómo las diversas problemáticas — de carácter político y financiero en el caso del gobierno y de orden social en el de la Iglesia- que enfrentaban ambas instancias dificultaron su actuación durante el tiempo que la epidemia se cebó sobre la población de Chiapas. Finalmente, establecer, después de un ejercicio de crítica documental, cuál pudo ser su impacto demográfico.

Palabras clave: epidemias, siglo XIX, registros parroquiales, indígenas, demografía.

\section{Abstract:}

In 1833, the Mexican Republic suffered the first cholera outbreak in its history. This article refers to the measures taken by the civic and religious authorities in Chiapas State in order to protect inhabitants of the region against the disease. It likewise aims to demonstrate how the different issues faced by both government — politics and financesand the Church — social order - hindered their action during the time that the epidemic spread throughout the population in Chiapas State. Lastly, after a critique of the documents, the article refers to its probable demographic impact.

Keywords: epidemics, nineteenth century, parish records, indigenous people, demography. 


\section{Introducción}

E

ntre los temas abordados por la historiografía mexicana sobre la primera mitad del siglo XIX, la epidemia de cólera de 1833 ha llamado la atención de muchos investigadores, que han estudiado las diversas rutas de su propagación por el territorio nacional —algunas de ellas completamente distintas de otros casos de epidemia durante el periodo virreinal—, así como el impulso que dio su presencia a la secularización de los entierros y a la elaboración de políticas sanitarias modernas por parte de los gobiernos, el gran temor que generó entre la población mexicana, el papel que jugaron las condiciones de insalubridad y pobreza que existían en los principales espacios urbanos del país en la propagación del vibrión y el impacto demográfico del padecimiento en los diferentes sectores de la sociedad. ${ }^{2}$

Aunque en las historiografías de varios estados de la república mexicana el cólera de 1833 ha sido objeto de estudio desde hace poco más de dos décadas, en el caso de Chiapas fue en tiempos muy recientes que este tema despertó el interés desde esa perspectiva. En tal sentido fue pionero el trabajo de tesis de licenciatura de José López Flores (López, 2010), quien fechó por vez primera el inicio de la epidemia en el estado y trazó la ruta que siguió por sus pueblos, villas y ciudades. Asimismo, utilizando documentación del Archivo Histórico Diocesano de San Cristóbal de Las Casas (AHDSC), López proporcionó algunos datos que permitieron hacernos una idea inicial del impacto demográfico en aquel tiempo. Posteriormente, Julio Contreras, retomando buena parte de esa información, escribió un breve artículo (Contreras, 2014) en el cual revisa algunas de las medidas adoptadas por el gobierno estatal para combatir la epidemia, y muestra al mismo tiempo algunos factores que pudieron facilitar su propagación en las localidades chiapanecas y su impacto demográfico en la entidad. De igual forma, y utilizando la información de la misma fuente, Contreras mostró algunos de los remedios que buscaron los habitantes del territorio chiapaneco, de forma infructuosa, para

\footnotetext{
${ }^{1}$ El cólera es una enfermedad que se manifiesta con una fuerte diarrea y vómitos que en poco tiempo pueden conducir al enfermo a la muerte. Es provocado por una bacteria de nombre vibrio cholerae, organismo que habita en el medio acuático y se halla unido a algas o a caparazones de los crustáceos. El ser humano también puede ser su reservorio. Se transmite por el consumo de agua contaminada con heces fecales o alimentos infectados.

2 Un completo y esclarecedor balance sobre los temas abordados en la historiografía de la epidemia de cólera de 1833 en México se encuentra en Alcalá (2012: 116-119). A los textos referidos por el autor pueden sumarse varios de los ensayos recogidos recientemente en Alcalá y Contreras (2014).
} 
combatir la epidemia, y encontró que el mal afectó por igual a los distintos estratos de la población local, incluidos los integrantes de las familias más encumbradas de la sociedad de ese tiempo.

Con miras a determinar el impacto del cólera en Chiapas en el periodo mencionado, el presente artículo, más que enfocarse en narrar la etiología de la enfermedad o descubrir los factores que facilitaron su propagación —aunque algo diremos al respecto-, intenta mostrar la respuesta social e institucional ante la epidemia y arrojar nuevos datos sobre su impacto demográfico. Así, en nuestro primer apartado analizamos las medidas sanitarias del gobierno de Joaquín Miguel Gutiérrez para combatirla y evaluamos de qué manera los conflictos políticos y la complicada situación financiera por la que atravesaba la hacienda pública chiapaneca impidieron a las autoridades estatales y municipales poner en práctica estas disposiciones con eficacia.

En vista de que tanto el gobierno civil como varios particulares apelaron a la Iglesia católica para que auxiliara espiritual y materialmente a quienes caían víctimas del padecimiento, en el segundo apartado exploramos en qué medida se vio limitada la colaboración de la Iglesia en esa coyuntura debido a los problemas que desde tiempo atrás venían afectando las relaciones entre los párrocos del obispado de Chiapas y su feligresía, sobre todo en aquellos curatos habitados mayoritariamente por indios.

Ya que la secularización de los entierros fue una de las principales acciones que los gobiernos promovieron para hacer frente a la contingencia del contagio, en el siguiente apartado nos dedicamos a analizar los alcances que tuvo la prohibición de sepultar a los muertos por el cólera dentro de las iglesias o en terrenos aledaños y qué tanto se cumplió con la orden de habilitar cementerios en las afueras de las poblaciones para inhumar a las víctimas.

Por último, en el apartado cuatro buscamos establecer cuál es el grado de fiabilidad de las fuentes que directa o indirectamente registran el número de decesos por la epidemia de 1833, con la finalidad de mostrar lo imprecisas que pueden llegar a ser y que es necesario conocer sus límites para evitar errores de interpretación a la hora de querer conocer la mortandad ocasionada por el vibrión. Aportaremos información con respecto al nivel de certidumbre que ofrecen estos registros y pasaremos a esbozar el impacto demográfico de los brotes de cólera de 1833 y 1835 en Chiapas. 


\section{El gobierno en tiempos del cólera}

Desde la primera mitad de 1833, cuando el cólera empezó a atacar a la población de diversas regiones de México (Carbajal, 2011: 2030-2039), las noticias que hacían referencia a esta enfermedad, y que narraban los devastadores efectos que dejaba a su paso, comenzaron a llegar a Chiapas. Así, en varias notas publicadas en periódico El Iris de Chiapas se aludió a su trayectoria por varios estados del país. $^{3}$

En vista de aquella amenazante circunstancia, el entonces gobernador Joaquín Miguel Gutiérrez dispuso una serie de prevenciones con el fin de enfrentar la epidemia en caso de que arribara al territorio chiapaneco. El 28 de septiembre de 1833 ordenó la creación de Juntas de Sanidad en todos los pueblos del estado, las cuales debían quedar integradas por los miembros de los ayuntamientos, el párroco del lugar y algunos vecinos. Supervisarían la limpieza de los espacios públicos y vigilarían que en los mataderos y los expendios de carne no se juntaran "charcos de sangre ni otras inmundicias" que, según se pensaba, facilitaban la propagación de la bacteria (El Iris de Chiapas, t.1, 48: 196).

Estas Juntas, en colaboración con los prefectos responsables de los departamentos en los que se dividía el estado (AHE-UNICACH, Manuscritos, t. 8, leg. 24), se encargarían de vigilar que en los mercados no faltaran los granos de primera necesidad y que estos no fueran acaparados ni vendidos a precios elevados. Asimismo, el gobierno ordenó a los prefectos que, en caso de que el cólera llegara a Chiapas, solicitaran préstamos a particulares para acopiar granos y distribuirlos ellos mismos entre la población a los precios establecidos, invirtiendo las utilidades de las ventas en el auxilio a los afectados (El Iris de Chiapas, t.1, 48: 196).

En este mismo sentido, el gobierno de Gutiérrez ordenó el cierre de caminos para evitar que el tránsito de personas facilitara la multiplicación del contagio. Así, en los primeros días de noviembre de 1833 se bloquearon las vías de enlace con el estado de Oaxaca. ${ }^{4}$ Este dato es de suma importancia pues, al parecer, fue una disposición determinante para frenar los contagios en Chiapas. La población adoptó de manera muy estricta esta medida en sus localidades. De este modo,

\footnotetext{
${ }^{3}$ Algunas de las noticias que se publicaron en El Iris de Chiapas y que aludían a la propagación del cólera por México y otras partes de América y Europa fueron analizadas en Contreras (2014) y Claps (2011).

${ }^{4}$ Años más tarde, en 1836, cuando el cólera empezó a hacer estragos en el Soconusco y Guatemala, el gobierno chiapaneco decretó el cierre de los caminos que unían a la entidad con Centroamérica (BMOB, AHC, Salubridad, t. IV, doc. 121, f. 1).
} 
los testimonios de la época coinciden en que los indios cerraron con palos y piedras las entradas de varios pueblos para evitar el ingreso de personas que pudieran diseminar la bacteria. De hecho, fue tan efectiva esta decisión que cuando en 1837 el Soconusco y Guatemala vieron aparecer los primeros brotes, algunos poblados chiapanecos colindantes con estas regiones, como Tonalá, volvieron a bloquear los accesos (AHDSC, FD, carp. 4417, exp. 29).

Al igual que ocurrió en otras áreas de México (Cuenya, 2006), las autoridades de Chiapas buscaron que, en los casos de fallecimiento por cólera, se enterraran los cuerpos en cementerios ubicados en las afueras de los poblados, pues, inspirados en las teorías aeristas, pensaban que las emanaciones de los cadáveres sepultados en las iglesias — como era la costumbre - eran perjudiciales para la salud de las personas que acudían a las celebraciones religiosas (AHE-UNICACH, Manuscritos, t. 8, leg. 23).

Así, el 25 de septiembre de 1833, el gobierno ordenó a los ayuntamientos la construcción de cementerios en parajes alejados de las poblaciones y dispuso que su construcción fuera cubierta con los Propios -es decir, los fondos financieros- de los municipios o, en caso de ser insuficientes, con el producto de colectas que las municipalidades deberían llevar a cabo (AHE-UNICACH, Manuscritos, t. 8, leg. 23).

Con todo, a pesar de las medidas que la administración de Joaquín Miguel Gutiérrez dispuso antes y durante la epidemia, poco era lo que podía hacer su gobierno para ponerlas en práctica con eficacia, debido, en primer lugar, al convulso escenario político por el que atravesaba el estado justo en ese momento en que hizo su aparición el brote, y a la falta de recursos de la hacienda pública. ${ }^{5}$

En efecto, aunque la situación política de Chiapas se había agitado desde inicios de la década de 1830, a raíz de la proclamación del Plan de Jalapa, que llevó a la presidencia de México a Anastasio Bustamante y a la gubernatura de Chiapas a José Ignacio Gutiérrez (Gutiérrez, 2013: 36-40), los conflictos en la entidad tomaron nuevos aires a partir de que en 1833 el gobierno de Joaquín Miguel Gutiérrez secundó las políticas secularizadoras del gobierno del vicepresidente Valentín Gómez Farías, generando un serio conflicto con el obispado de Chiapas y con algunas facciones que mostraron su apoyo al clero. Así, a finales de 1833 varios vecinos de la capital chiapaneca, agrupados en torno al Plan de San

\footnotetext{
${ }^{5}$ La falta de recursos financieros también dificultó la adopción de las medidas sanitarias para combatir el cólera en otras regiones del país. Sobre el caso de la Ciudad de México véase Márquez, 1994: 279.
} 
Cristóbal, se levantaron en armas a favor de la Iglesia, atizando aún más la tensa situación política por la que atravesaba Chiapas (Torres, 2014: 274-292).

Una de las principales consecuencias de la inestabilidad política que padecía el estado fue que el erario chiapaneco, incapaz de afianzar su control sobre el territorio estatal y, por tanto, de crear fuentes de ingreso mediante nuevos impuestos, vio cómo sus fondos eran cada vez más insuficientes a la hora de cubrir sus gastos, hecho que se convirtió en uno de los principales obstáculos para hacer efectivas las medidas contra la epidemia.

En este sentido, a inicios de 1833 se previó un déficit en las finanzas estatales de 30000 pesos, que, se dijo, "ha de pesar como siempre sobre los pueblos". 6 En vista de la falta de recursos, el mismo Gutiérrez reconoció que su gobierno no podría evitar el contagio en "los pueblos más infelices", y "ni siquiera podría evitar en parte sus penurias por la falta de fondos disponibles" (El Iris de Chiapas, t. 2, 8: 3).

La necesidad del gobierno de conseguir recursos adicionales para enfrentar el cólera lo llevó a disponer de los capitales que habían pertenecido a la Sociedad Económica de Amigos del País de Chiapas, desaparecida por orden del gobernador en abril de 1833 (Torres, 2014: 275). Sin embargo, dado que se requerían recursos extraordinarios para combatirlo, Gutiérrez ordenó la creación de comisiones encargadas de la recolección de fondos, bajo el rótulo de Juntas de Caridad.

En el decreto por el que se ordenó la formación de estas, el gobernador dijo estar "tristemente convencido" de que los fondos de los que disponía la hacienda pública del estado no alcanzaban para reunir alimentos, remedios y demás auxilios necesarios para proteger a las personas que pudieran ser atacadas; apeló entonces a la caridad "de las personas acomodadas" para que apoyaran el combate de la epidemia, y advirtió que, en caso necesario, solicitaría préstamos voluntarios o forzosos para mantener las medidas sanitarias diseñadas al propósito (AHE-UNICACH, Manuscritos, t. 32, f. 150; Contreras, 2014: 121-122).

La estrategia del gobierno, pues, consistió en crear entidades que, bajo su supervisión, pudieran operar y poner en práctica las medidas de combate, al tiempo que buscó involucrar en la operación de ambas juntas —las de caridad y sanidad - a diversas corporaciones y a particulares, los cuales recaudarían los

\footnotetext{
${ }^{6}$ El gobierno de Gutiérrez indicó que por la falta de recursos en la hacienda pública del estado no se habían podido "poner los prefectos y subprefectos que se necesitan y lo que es más sensible ni escuelas ni otros establecimientos de primera necesidad" (El Iris de Chiapas, t. 1, 27: 108).
} 
capitales adicionales que fueran necesarios para que las Comisiones de Sanidad funcionaran correctamente.

De hecho, la Iglesia fue una de las principales instituciones involucradas en la atención de los pueblos que pudieran ser atacados.

\section{La Iglesia de Chiapas frente a la epidemia}

Desde que las autoridades del obispado de Chiapas se enteraron de la amenaza que representaba el cólera, se mostraron dispuestas a colaborar con el gobierno estatal para proteger a la población (AHDSC, FD, carp. 3965, exp. 34). El obispo de Chiapas, fray Luis García Guillén, a pesar de los conflictos que lo enfrentaron con el gobernador Joaquín Miguel Gutiérrez (Torres, 2014: 279-297; Gutiérrez, 2013: 39-40), se mostró colaborativo con las medidas sanitarias que dispuso la administración pública. Sabemos, por ejemplo, que el prelado apoyó la orden dada por las autoridades de no sepultar en las iglesias a las víctimas de la epidemia y de llevar a cabo las inhumaciones en cementerios alejados de las poblaciones (AHDSC, FD, carp. 4819, exp. 34).

Además, imploró públicamente la piedad divina para que la epidemia no invadiera el estado. En los primeros días de noviembre de 1833, fray Luis ordenó el traslado en procesión de la Virgen de la Caridad — protectora de los ladinos de Chiapas, en particular de San Cristóbal (Viqueira, 2106) - de su templo a la catedral, en donde se le ofició un novenario de misas para suplicarle que librara a la población del embate del cólera (AHDSC, FD, carp. 5006, exp. 11).

Sin embargo, los auxilios espirituales no fueron lo único que la población buscó en la Iglesia. Ante la agónica falta de recursos que sufrían los erarios de los pueblos de Chiapas, las Juntas de Caridad solicitaron el apoyo del obispado para que este los dotara de los medios para hacer frente a la inminente llegada del brote. Tras varios intentos infructuosos por conseguir recursos dentro de su pueblo, la Junta de Caridad de Chamula pidió al cabildo eclesiástico

Extender su mano benefactora, dispensando los auxilios de suma necesidad [...] para determinar [...] las medicinas, alimentos y socorros espirituales para librar de alguna manera a estos feligreses de las negras garras que los amaga(n) (AHDSC, FD, carp. 513, exp. 3). 
Y a pesar de la ayuda que las Juntas de Caridad o particulares pidieron a la Iglesia católica, el papel que esta institución desempeñó durante la epidemia no parece haber sido demasiado sobresaliente. De hecho, aunque en un trabajo reciente sobre esta plaga en Chiapas se ha indicado que los ministros eclesiásticos "consolaron repetidas veces a los enfermos" y que "el papel de la Iglesia fue de gran importancia antes, durante y después de la epidemia" (Contreras, 2014: 120), los registros que dan cuenta de la actuación de los párrocos y curas del obispado de Chiapas durante el cólera de 1833 nos presentan una historia distinta.

Aun cuando el papel del clero en las principales ciudades del estado fue relativamente destacado por su actuación en las Juntas de Sanidad, e incluso se distinguió por aportar recursos para socorrer a las víctimas, ${ }^{7}$ sin embargo, en el resto de los pueblos de Chiapas, en los cuales la relación de los párrocos con sus fieles - mayoritariamente indios - se había deteriorado desde el último tercio del siglo XVIII (Viqueira, 2007), la actuación de la iglesia ante el brote estuvo marcada por la ausencia de ministros religiosos o por la resistencia que algunos de estos manifestaron para auxiliar a la población que caía presa de la enfermedad.

Sobre la escasez de curas sabemos, por ejemplo, que el 31 de enero de 1834, Tomás Aguilar, párroco de Chilón, informó al chantre del obispado que el sacerdote del vecino pueblo de Yajalón, José María Mazariegos, había muerto, situación que dejaba sin un ministro a las almas que estaban a su cargo, ya que él

de ninguna suerte puedo auxiliarlos pues [... no tengo ministro de descanso, me hallo con una pierna mala, que no puedo andar a caballo. Por cuyo motivo estoy por horas aguardando el ministro que he pedido para que me ayude y pueda resistir (AHDSC, FD, carp. 4078, exp. 1, f. 34).

Pero el temor que generó la llegada del vibrión hizo que uno de los coadjutores del citado vicario "se hubiese ocupado de mucho terror y espanto en los momentos que la arrasadora peste atacó a los habitantes en el pueblo de Oxchuc" y provocó que este se separara de su cargo en febrero de 1834.

De hecho, la decisión de algunos curas de abandonar a sus fieles ante el embate de la epidemia parece haberse dado en varios de los pueblos del obispado de Chiapas. Por ejemplo, en febrero de 1834, Joaquín Esponda denunció que el sacerdote de Acala huyó del pueblo a los pocos días de haber aparecido la

\footnotetext{
${ }^{7}$ En noviembre de 1833 el convento de Santo Domingo de San Cristóbal donó 10 pesos a la Junta de Caridad de aquella ciudad (El Iris de Chiapas, t. 2, 8: 3).
} 
peste en la localidad (AHDSC, FD, carp. 4078, exp. 1). La principal causa por la que al parecer decidió distanciarse fue que la mayor parte de su feligresía se encontraba viviendo en haciendas y rancherías alejadas entre ocho y diez leguas de la sede parroquial, y le resultaba bastante complicado cubrir las necesidades espirituales de todas estas personas.

De igual forma, en los primeros meses de 1834, los ayuntamientos de Simojovel, San Pedro y Santa Catarina Huitiupán denunciaron que el fraile Agustín Aguilera "desamparó los pueblos el 18 de enero, dejándonos en lo más furiosos de la peste, (y) dejó a un padre franciscano, pero no dio abasto. Murieron y siguen muriendo sin confesión" (AHDSC, FD, carp. 841, exp. 1, ff. 1-3). Además, los indios señalaron en su carta los constantes abusos que el cura cometía en su contra, tildándolo de "hombre déspota y cruel".

Asimismo, el monto exiguo que percibían los párrocos por la atención de los curatos a los que estaban asignados quebrantó aún más su vocación sacerdotal durante el embate de la epidemia. Por ejemplo, el vicario de Huixtán se quejó de que los pueblos a los que estaba adscrito ni siquiera producían "la miserable dotación de veinte y cinco pesos mensuales que me están asignados, ni proporcionan los auxilios precisos para pasar la vida con honestidad, cuya circunstancia obligó a mi antecesor [...] a dimitir este destino" (AHDSC, FD, carp. 4078, exp. 1, f. 1). Para colmo de males, el cólera mermó aún más los ingresos de los curas. Así, cuando la epidemia apareció en San Andrés, los indios de este pueblo se negaron a seguir pagando las contribuciones a su párroco (Ortiz, 2005: 147).

Con todo, un ejemplo muy ilustrativo de la desesperación y el hartazgo que invadieron a algunos sacerdotes cuando la epidemia se abatió sobre algunos curatos indios del obispado de Chiapas, lo representa fray Mariano de Mora, cura interino de la parroquia de Tapalapa.

Según se lee en una extensa carta que envió a las autoridades del obispado (AHDSC, FD, carp. 3572, exp. 25), a raíz de que el cólera apareció en el pueblo de Quechula, en noviembre de 1833 (AHDSC, FP, Defunciones, caja 310, libro 2, ff. 195-197v), los feligreses cerraron los caminos que llevaban a sus pueblos, bloqueando "todos los recursos de su comercio e industria". Esta situación se agravó cuando la epidemia finalmente atacó su parroquia en la Semana Santa de 1834, provocando que los habitantes de Pantepec y San Bartolomé Comistahuacán cerraran también las comunicaciones con los pueblos de su curato.

Todo indica que la grey de fray Mariano aprovechó la psicosis que desató la epidemia para liberarse de la pesada carga de mantener a su párroco, pues este 
aseguró que la dificultad de llegar a su feligresía para administrarle sacramentos también hacía imposible cobrarles las raciones que le debían proporcionar, mermando de forma dramática sus ingresos.

Además, fray Mariano argumentó que ordenarle a los indios que le permitieran el paso a sus pueblos resultaba muy peligroso en vista de que "nadie que conozca la ignorancia y abusos de los indios, me podrá culpar en no haber mandado se abrieran" y que burlar los bloqueos era casi una misión suicida, pues si bien "pudiera entrar a los (pueblos) que están actualmente apestados, no podría salir sin poner en riesgo mi vida entre estos semirracionales" (AHDSC, FD, carp. 3572, exp. 25).

Los comentarios de Mora acerca del salvajismo de su comunidad son un buen ejemplo de la forma en la que los párrocos de la época, hartos de la convivencia con sus feligreses, estructuraban el discurso que dirigían a sus superiores, de tal manera que este buscaba conmover a las autoridades eclesiásticas para que accedieran a cumplir las peticiones del cura (Viqueira, 2007). De hecho, el motivo de la exposición que fray Mariano hizo al obispado era para solicitar, lo antes posible, ser trasladado a otra parroquia en la cual pudiera desempeñar sus funciones de manera más cómoda.

En fin, las historias que hemos narrado han querido mostrar que si bien durante un buen tiempo los párrocos de Chiapas habían, mal que bien, soportado la lejanía de sus feligreses, la falta de personal que colaborara con ellos en las tareas espirituales, las pocas rentas que percibían y su incapacidad para entablar buenas relaciones con los fieles a su cargo — casi todos indios_, la llegada del cólera a sus pueblos hizo de su estancia en ellos algo insoportable, debido a que la demanda de servicios espirituales se incrementó, al tiempo que el desquiciamiento de la vida cotidiana causado por la epidemia representó para los indios un buen pretexto para dejar de pagar las limosnas a sus curas, con lo cual se vieron mermados sus ingresos y algunos de estos se vieron impelidos a tomar la decisión de solicitar el auxilio del obispado o, en otros casos, de abandonar sus parroquias o a pedir su traslado a otros curatos que consideraran menos inhóspitos. ${ }^{8}$

\footnotetext{
${ }^{8}$ La complicada historia de las relaciones de los párrocos con su feligresía india a lo largo del siglo XIX en Chiapas ha sido estudiada en detalle por Ortiz (2003). Asimismo, Viqueira (2007), centrando su atención en la parroquia de San Andrés, demuestra lo tensas que podían ser estas relaciones, el hartazgo que los párrocos podían llegar a sentir a causa de ellas y la actitud retadora de los indios, cuyo propósito era rendir la vocación sacerdotal de sus ministros.
} 
Así, tanto los problemas en que se vieron envueltas las autoridades civiles para obtener los medios —sobre todo financieros - y enfrentar la epidemia, como los muchos contratiempos que vivieron los ministros del obispado de Chiapas para socorrer a la parte de su grey alcanzada por el cólera, afectaron poderosamente la aplicación de varias de las medidas que se habían dispuesto para su combate. De hecho, seguirle la pista al proceso de habilitación de cementerios civiles para enterrar a las víctimas de la epidemia nos permite ver cómo los varios fracasos combinados de ambas instituciones influyeron en los limitados alcances que tuvo la aplicación de estas medidas.

\section{La secularización de los entierros}

A pesar de los conflictos que a inicios de la década de 1830 enfrentaron a la Iglesia con la administración de Joaquín Miguel Gutiérrez (Torres, 2014: 279-297), y que desembocaron en la expulsión del obispo de Chiapas, fray Luis García Guillén, en mayo de 1834 (Torres, 2014: 296; Flores, 1978: 114-115), el gobierno local buscó el apoyo del clero para poner en práctica algunas medidas sanitarias para enfrentar los estragos de la epidemia de cólera. Uno de los asuntos que quedaron en manos tanto de las autoridades civiles como de las eclesiásticas fue el de la prohibición de sepultar a las víctimas de la epidemia en las iglesias y de procurar que estas se enterraran en cementerios alejados de los poblados.

Desde finales del periodo virreinal, las ideas ilustradas que comenzaron a circular por los territorios del imperio español habían puesto en entredicho la vieja costumbre de inhumar dentro de las iglesias o en terrenos inmediatos a estas. ${ }^{9}$ Por ejemplo, hacia 1814, el obispo de Chiapas, Ambrosio Llano, había hecho circular por su diócesis un decreto, expedido por las Cortes de Cádiz, mediante el cual se prohibían los entierros dentro de las iglesias y se pedía a los curas párrocos la habilitación de camposantos fuera de los poblados (AHDSC, FD, carp. 4013, exp. 9). Años más tarde, la práctica de sepultar en las iglesias fue criticada con dureza por el obispo Salvador San Martín, quien indicó, tras una visita que realizó a San Bartolomé de los Llanos, que al interior del templo principal del pueblo: "los miasmas corrompidos ocupan la atmósfera (...), de modo que para

\footnotetext{
9 Sobre las creencias que habían llevado a la cristiandad occidental a preferir la cercanía a los lugares de culto para ser inhumados, véase el clásico trabajo de Ariès (1984: 42-55).
} 
evitar otros funestos resultados ha precisado el párroco mandar que por toda una noche se mantuviere abierta [la iglesia]" (AHDSC, FD, carp. 4032, exp. 11, f. 2).

Aunque la llegada de la independencia y los convulsos años que habían seguido a esta dificultaron que el proyecto de terminar de una vez por todas con los entierros dentro de las iglesias pudiera llevarse a cabo, la aparición del cólera en 1833 hizo impostergable esta medida. De este modo, al igual que en otros estados mexicanos, la administración de Joaquín Miguel Gutiérrez ordenó a los ayuntamientos vigilar que los muertos dejaran de ser sepultados en los templos.

Así, mientras que las corporaciones municipales se encargarían de elegir los terrenos para la habilitación de los nuevos cementerios, tocaría a las autoridades religiosas de cada población la tarea de bendecir los nuevos (AHDSC, FD, carp. 322, exp. 2) y de animar a la población para que, en vez de "recibir esta medida con la repugnancia nata a tal novedad en pueblo poco instruido, se persuadan de que es indispensable y necesaria para la propia conservación [de la vida]" (AHDSC, FD, carp. 2619, exp. 2).

Sin embargo, el primer obstáculo que enfrentó la adopción de esta medida fue la demora con la cual procedieron los ayuntamientos para abrir los panteones civiles. Por ejemplo, José Trejo denunció la tardanza con la que había procedido el ayuntamiento de San Lucas para abrir un cementerio en el cual sepultar a las víctimas del cólera (AHDSC, FD, carp. 322, exp. 2, ff. 1-1v). Asimismo, en San Felipe, la nula información que poseía su Junta de Sanidad acerca de los síntomas del cólera ocasionó que el primer muerto por esta enfermedad fuera enterrado en el tempo del pueblo. De hecho, aunque esta defunción se registró el 3 de diciembre de 1833, no fue hasta el 28 de ese mes cuando se inhumó el primer cuerpo en el cementerio civil (AHDSC, FP, Defunciones, caja 422, libro 5). Asimismo, en Quechula los primeros entierros en el cementerio civil se verificaron el 29 de noviembre de 1833, es decir, 20 días después de haber aparecido la epidemia en esa localidad (AHDSC, FP, Defunciones, caja 310, libro 2, ff. 195-197v).

Además, el hecho de que gran parte de la población de algunas regiones de Chiapas habitara dispersa en caseríos contribuyó a que muchas de las víctimas fueran inhumadas en los sitios que habitaban. Por ejemplo, en Quechula se tuvo noticia de personas enterradas en campo abierto, a la orilla de los caminos, y en San Felipe se supo de varias que fueron sepultadas "en los montes".

Asimismo, en Tuxtla los cuerpos de muchas de las víctimas que vivían en medio del campo, en ranchos y haciendas, quedaron en fosas improvisadas que ninguna autoridad recoció como cementerios (AHDSC, FD, carp. 3263, exp. 10). 
Pero también, los nuevos espacios funerarios no necesariamente cubrieron los requerimientos que las autoridades habían indicado en un principio. Así, uno de los cementerios abiertos en Tuxtla se instaló al lado de la iglesia de San Roque, pasando por alto la orden gubernamental de que los entierros se hicieran en terrenos alejados de los pueblos para evitar cualquier contacto.

De hecho, tan parco fue el control que pudieron establecer las autoridades civiles sobre el funcionamiento de los cementerios que, de nuevo en el caso del de Tuxtla, una vez que la epidemia pasó, el improvisado panteón fue olvidado junto con las personas que en él estaban sepultadas. Algunos años más tarde, un nuevo párroco de esa ciudad escribió alarmado que esos pobres muertos "yacen hasta hoy en campo profano"; pero lo que le parecía más terrible era que "[los muertos estaban] sirviendo de germen a las milpas y calabazas que en conmemoración de esos fieles difuntos hacen en parte del campo todos los años".

Con todo, la habilitación de cementerios civiles parece haberse verificado en la mayor parte de los pueblos, villas y ciudades en Chiapas. Así, en los libros de difuntos de más de una parroquia se anotó, en la mayoría de los casos, que los fallecidos por el cólera se habían sepultado en los "cementerios de limosna" o en "el camposanto civil" (AHDSC, FP, Defunciones, caja 303, libro 6, ff. 88-107; AHDSC, FP, caja 205, libro 4; AHDSC, FD, carp. 3158, exp. 3, f. 3v).

Sin embargo, es muy complicado conocer con exactitud la eficacia de la medida, debido a que las autoridades estatales — posiblemente porque se hallaban más ocupadas atendiendo los conflictos políticos en los que estaban inmersaspoco pudieron hacer para verificar que las Juntas de Sanidad y las municipalidades cumplieran a cabalidad con sus funciones de supervisar el entierro de las víctimas de la epidemia en los cementerios.

De hecho, los registros de defunciones, tal como sucedía desde hacía mucho tiempo, siguieron siendo llevados por los párrocos, los cuales, incapaces de controlar eficazmente a su grey, tampoco llevaron un control estricto de las defunciones causadas por el cólera.

Todo lo anterior abonó a la aparición de un importante subregistro en los libros parroquiales que es indispensable conocer debido a que estos, o los documentos elaborados con base en los datos contenidos en ellos, constituyen la principal fuente para establecer, de manera aproximada, la magnitud del impacto demográfico de la epidemia de cólera de 1833-1835 en el estado. A esta tarea dedicamos nuestro último apartado. 


\section{El impacto demográfico de la epidemia}

Aunque contamos con algunos de los libros de defunciones de las parroquias del obispado de Chiapas durante los años de epidemia de cólera (1833, 1834 y 1835), la mayor parte de las fuentes que nos permiten conocer el número de muertos que esta dejó, el sexo de las víctimas y sus edades, son producto de un conjunto de informes que los párrocos de Chiapas levantaron en 1849 a solicitud del gobierno de la república. En ese año, ante la inminencia de un nuevo embate epidémico, el gobierno del presidente Joaquín de Herrera pidió a los obispados del país proporcionar información sobre el número de muertos a causa de la primera etapa (la de 1833), con la finalidad de diseñar medidas más eficaces para combatir el nuevo ataque del vibrión (Carbajal, 2011: 2029).

El 16 de febrero de 1849, el obispado de Chiapas turnó a todos sus párrocos esta orden (AHDSC, FD, carp. 2631, exp. 8). En los siguientes meses, varios curas procedieron a revisar los libros de defunciones de sus parroquias con la finalidad de entregar la información que les fue solicitada. El problema con los informes de 1849 es que la fiabilidad de sus datos está supeditada a la calidad de los registros asentados en los libros, los cuales, dada la ausencia de ministros en algunos de los curatos del obispado o de la incapacidad de estos para llevar un control estricto de sus parroquianos, no necesariamente brindan una información correcta del número de decesos causados por el cólera. Veamos por qué.

En Tenejapa, el párroco de 1849 advirtió que en el libro de difuntos solo se encontraban aquellas personas que fueron enterradas en el camposanto del pueblo, pues muchas más fueron inhumadas por sus familiares en los montes, "sin que hubieran dado noticia de esto al párroco de aquel entonces" (AHDSC, FD, carp. 3158, exp. 3). Los registros de Socoltenango presentaron un problema idéntico, pues estos excluían "el inaveriguable número de los que fallecieron fuera de las poblaciones y que no estuvieron al alcance del párroco" (AHDSC, FD, carp. 2043, exp. 2).

De igual forma, el de Yajalón indicó que el libro de defunciones de su curato correspondiente a los años del cólera presentaba tantas deficiencias en su elaboración, que para redactar su informe tuvo que basarse en "los informes que he tomado de los vecinos de este pueblo", a través de los cuales pudo fechar 
— de forma errónea, por cierto— ${ }^{10}$ el inicio de la epidemia y localizar tan solo parcialmente el número de muertos que esta dejó, pues indicó que "En todo ese tiempo, todos sobrecogidos de terror [...] solo cuidaban de sus personas y sus familias y, como no había cura que los auxiliara, nadie llevaba la cuenta de las víctimas que hacía aquella terrible peste" (AHDSC, FD, carp. 3209, exp. 4, f. 1v).

Por otro lado, algunos libros de difuntos ni siquiera fueron hallados al momento que se iban a elaborar los informes de 1849 , bien porque, dado el desorden que debía imperar en los archivos parroquiales, estos registros no se hallaron, o bien porque estos nunca fueron elaborados. En San Bartolomé de Los Llanos y Amatenango, por ejemplo, se carecía de datos sobre los muertos por el cólera en sus respectivos archivos parroquiales (AHDSC, FD, carp. 395, exp. 9 ; AHDSC, FD, carp. 5673, exp. 11).

Otro problema de los registros de defunciones era que en el obispado de Chiapas había predominado una notable heterogeneidad en la forma en que se habían levantado las partidas de difuntos. ${ }^{11}$ En algunas solo se anotaba el nombre de pila y los apellidos de la persona fallecida, sin que se escribiera la fecha y la causa de su muerte, como sucedió en Cancuc y Petalcingo (AHDSC, FP, Defunciones, caja 59, libros 3 y 4; AHDSC, FP, Defunciones, caja 303, libro 6, ff. 88-107).

Esta misma heterogeneidad reinó en los informes de 1849. Así, mientras que algunos párrocos detallaron en sus informes los nombres de las víctimas de la epidemia, la mayoría se limitó a entregar un cuadro en donde clasificaron a los difuntos por sexo y edad (es decir, hombres, mujeres y, en algunos casos, párvulos). Además, hubo otros que agregaron a estas dos categorías las de "casados", "viudos" y "solteros".

Con todo, dado que estos informes constituyen la principal — cuando no la única - fuente de información de la que disponemos los historiadores hasta el día de hoy para conocer el impacto demográfico de la epidemia de cólera de 1833-1835 en los pueblos de Chiapas, hemos decidido utilizar las cifras que proporcionan, advirtiendo al lector que estos datos, tal como los coetáneos de la

\footnotetext{
10 Según el párroco, el cólera habría arribado a Yajalón el 7 de junio de 1833. Sin embargo, este dato no puede ser correcto, debido a que para esas fechas la epidemia aún no atacaba a los estados vecinos de Tabasco y Campeche y, por tanto, es imposible que haya llegado a Chiapas en esas fechas tan tempranas (AHDSC, FD, carp. 3209, exp. 4).

${ }^{11}$ En la parroquia de San Andrés, por ejemplo, el registro de las víctimas de la epidemia de cólera de 1834 fue levantado por el fiscal de la iglesia (AHDSC, FD, carp. 769, exp. 4, f. 2)
} 
época lo afirmaron, brindan una información parcial debido a "la falta de algunas partidas" (AHDSC, FP, Defunciones, caja 422, libro 5, f. 29). ${ }^{12}$

Ahora bien, un último problema que se debe resolver antes de pasar a mostrar cuál fue el impacto demográfico de la epidemia de cólera de 1833-1835 en Chiapas tiene que ver con que carecemos de datos confiables acerca del número de habitantes que había en la entidad en el momento del arribo del vibrión.

Tras la consumación de la independencia, los empadronamientos sistemáticos de la población en Chiapas llegaron a su fin. Los pocos datos de los que disponemos datan de los años de 1824, 1828 y 1831 (cuadro 1 y gráfica 1). Una lectura rápida de las cifras que arrojan estas fuentes indica que durante estos años se registró una disminución considerable en el número de habitantes en Chiapas, que a primera vista sugeriría un decrecimiento de la población. No obstante, al analizar esta información con ojos críticos se observa una situación muy diferente. Veamos.

Cuadro 1. Población total registrada en Chiapas, 1813-1837.

\begin{tabular}{lc}
\hline Año & Población total de Chiapas, 1813-1837 \\
\hline 1813 & 130298 \\
1824 & 172944 \\
1828 & 109401 \\
1831 & 122914 \\
1837 & 119000 \\
\hline
\end{tabular}

Fuente: Para 1813 y 1824: Obara y Viqueira (2017: Base de datos 2); para 1828: BMOB, AHC, Memorias, t. III, doc. 52; para 1831:BMOB, AHC, Censos, t. IV, doc. 14, f. 1 y para 1837: Contreras (2014: 134).

Gráfica 1. Población total registrada en Chiapas, 1813-1837

\footnotetext{
${ }^{12}$ Asimismo, el párroco de Tumbalá indicó que en su informe sobre el cólera de 1834 en su parroquia "va reducido el número de los [muertos] que hubo desde el principio hasta el fin del repetido mal" (AHDSC, FD, carp. 1856, exp. 3, f. 3).
} 


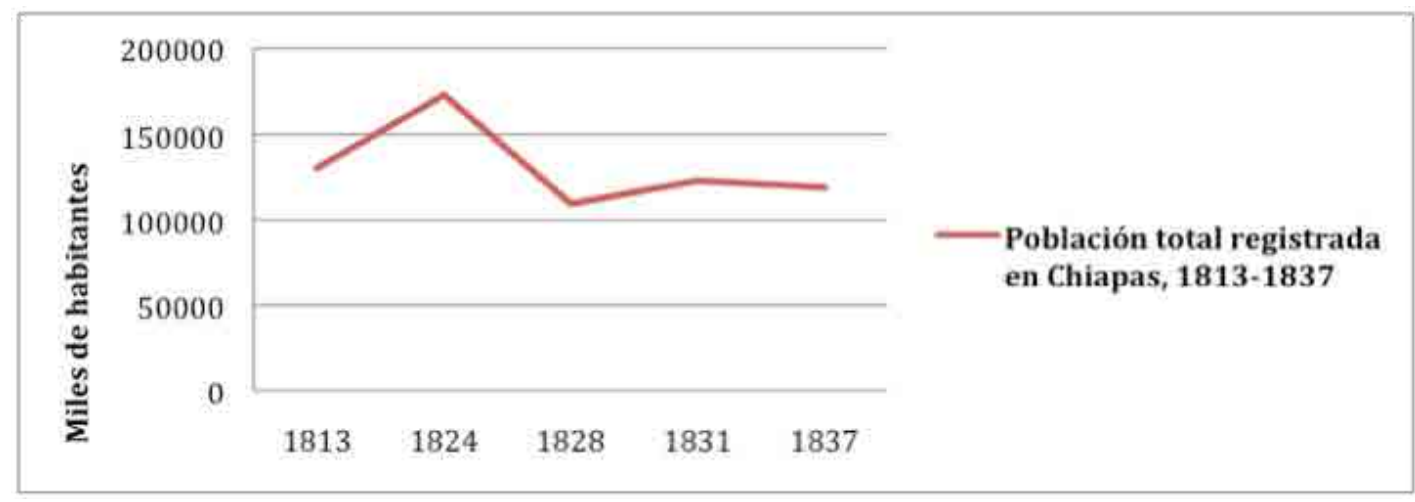

Fuente: Cuadro 1.

Es posible que las epidemias que se cebaron en estos años sobre distintas regiones de Chiapas hayan mermado en algo la población. ${ }^{13}$ Sin embargo, esta reducción tan drástica tiene otras razones. Para empezar, los pueblos del Soconusco - que sí se incluyen en los conteos anteriores- dejaron de empadronarse debido a que esta región aún no resolvía el dilema de si se integraba a México o continuaba formando parte de Centroamérica. Además, tras la consumación de la independencia se dio al traste con los eficientes procedimientos de empadronamiento de la población que se habían conseguido en los últimos años del dominio español y que habían dado como resultado una considerable alza en las diversas matriculas que registraban indirectamente el número de habitantes de Chiapas — sobre todo de los indios (Obara y Viqueira, 2017: 140-158)_. En consecuencia, el subregistro de personas creció de forma desmesurada después de 1821.

Por ejemplo, en la memoria del gobierno de Chiapas de 1828 se mostró la inexistencia de cifras sobre el número de habitantes de 13 pueblos. ${ }^{14}$ De hecho, esta falta de datos impactó poderosamente en las finanzas de la hacienda pública de Chiapas, debido a que era con apoyo en estos que se calculaba la base

${ }^{13}$ Por ejemplo, sabemos que entre 1826 y 1829 una epidemia de sarampión y otra de viruela atacaron varios de los pueblos de Chiapas (Ruz, 1992: 294; BMOB, AHC, Memorias, t. III, doc. 52). Asimismo, Óscar Barrera, en una recientemente defendida tesis doctoral en el Centro de Estudios Históricos de El Colegio de México (Barrera, 2017), ha demostrado que durante el periodo que va de 1826 a 1837 los pueblos de las Terrazas de los Altos fueron atacados por una epidemia de sarampión, la de cólera que acá estudiamos y una más de viruela que apareció en 1837 (Barrera, 2017: 143-145)

14 Estos eran: Chamula, Magdalena, Chapultenango, Nicapa, Sunuapa, Ostuacán, Sayula, Tapilula, Comistahuacán, Ixhuatán, Oxchuc, Tenejapa y Huixtán (BMOB, AHC, Memorias, t. III, doc. 52). 
fiscal de la capitación, renta cuyos ingresos habían venido disminuyendo en los últimos años por los problemas que padecían las autoridades para cobrarla.

Aunque es posible que este subregistro se haya reducido en los años siguientes, para 1833 se hizo apremiante la necesidad de un nuevo conteo general de la población del estado que permitiera al erario estatal aumentar sus ingresos. En este sentido, el gobernador Joaquín Miguel Gutiérrez ordenó, en junio de 1833, que se "rectificaran" los padrones de los pueblos y se formara un nuevo censo general que sirviera para "el aumento y arreglo de la hacienda pública" (BMOB, AHC, Gobierno de Chiapas, t. IV, doc. 91, 10 ff.). Para desgracia del gobernador, todo indica que la llegada del cólera y la convulsa situación política por la que atravesaba el estado en aquellos momentos impidieron la realización de tan anhelado conteo.

Con todo, nuestros datos indican que entre 1829 y 1831 se logró empadronar a un mayor número de habitantes. Así, un documento del que no sabemos su origen y la finalidad que tuvo - aunque presumimos que tuvo una utilidad fiscal-, fechado en 1831 (BMOB, AHC, Censos, t. IV, doc. 14, f. 1), indica que en el estado había 122914 habitantes, 15000 más que tres años antes. De esta forma, dado que esta cifra parece estar basada en los distintos conteos que se hicieron de los pueblos, villas y ciudades de Chiapas en los años anteriores al cólera, ${ }^{15}$ hemos decidido utilizarla para calcular cuál fue el impacto demográfico de la epidemia. ${ }^{16}$

Ahora bien, con base en las consideraciones anteriores, pasemos a ver el recorrido que el cólera siguió en Chiapas y la mortandad que dejó a su paso. ${ }^{17}$

\footnotetext{
${ }^{15}$ Aunque el documento de 1831 no especifica el tamaño de la población para cada una de las localidades del estado, sí informa del número de habitantes de la ciudad de San Cristóbal, el cual coincide plenamente con la cifra que desde 1828 se tenía sobre esta localidad (7 022 "almas"). Por ello, consideramos que el cálculo en el que está basado el documento de 1831 se calculó a partir de la suma de los distintos conteos que se habían realizado en los últimos años en los diferentes pueblos del estado.

${ }^{16}$ Contreras (2014: 134) utilizó un censo de 1837 para calcular el impacto demográfico de la epidemia de cólera de 1833-1835 en Chiapas. Sin embargo, nosotros no hemos utilizado esa fuente debido a que obviamente ya habían sido descontados los muertos a causa de la epidemia y restar a esos totales de nuevo nuestras cifras de difuntos crearía una imagen ciertamente muy imprecisa.

${ }_{17}$ Para seguir el recorrido de la epidemia, hemos decidido agrupar a los pueblos de Chiapas según la regionalización que proponen Tadashi Obara y Juan Pedro Viqueira (2017, mapa 10), quienes dividen el territorio de Chiapas en diversos paisajes humanos. Las frecuentes relaciones entre los habitantes de los pueblos que integran cada uno de estos paisajes, a nuestro juicio, permiten comprender mejor por qué el cólera siguió las rutas que en seguida veremos.
} 
Procedente ${ }^{18}$ del istmo de Tehuantepec, en Oaxaca, ${ }_{19}^{19}$ el cólera arribó a la ciudad de Tuxtla el 8 de noviembre de $1833 .{ }^{20}$ Como lo han indicado atinadamente José López y Julio Contreras, la imposibilidad de cortar la comunicación con esa región, sobre todo por los constantes movimientos de tropas, causaron el ingreso del vibrión al estado (López, 2010; Contreras, 2014: 121-122). Durante las primeras semanas la enfermedad mató a 55 personas. Aunque no disponemos de cifras exactas sobre el número total de personas que murieron en esta ciudad a consecuencia de la epidemia, algunos contemporáneos calcularon el número de decesos en más de 1000 (AHDSC, FD, carp. 3318, exp. 190, f. 1), cifra que quizá no esté tan alejada de la realidad, debido a que Tuxtla se había convertido en uno de los principales centros políticos y económicos del estado, atrayendo a una importante cantidad de pobladores.

De hecho, el constante tránsito de personas hacia Tuxtla convirtió a esta población en uno de los principales centros a partir de los cuales se diseminó la epidemia. En Ocozocoautla, por ejemplo, el cólera arribó procedente de Tuxtla el 9 de noviembre, y en las siguientes semanas mató a 210 personas. Según se dijo, todos los fallecidos se habían contagiado en aquella ciudad, a la cual habían viajado para resolver diversos asuntos (AHDSC, FD, carp. 1201, exp. 1, f. 1).

De Tuxtla la epidemia pasó hacia la sierra de Tecpatán, en donde atacó al pueblo de Quechula, quitando la vida a 130 personas (Contreras, 2014: 123). Un mes más tarde, Tecpatán se vio afectado con165 defunciones. En noviembre de 1833 el cólera pasó al pueblo de Chiapa en donde dejó 204 finados, y luego se trasladó a varios pueblos del corredor zinacanteco, entre ellos San Gabriel, desde el cual avanzó a Soyaló en diciembre de ese año, causando 42 y 32 fallecimientos, respectivamente. ${ }^{21}$

\footnotetext{
${ }^{18}$ La fuente de donde hemos tomado la fecha aproximada de inicio de la epidemia en cada pueblo — que más bien es la fecha en la cual se registró el primer muerto- se indica en el apéndice 1.

${ }_{19}$ Procedente de Puebla, el cólera llegó a Oaxaca en octubre de 1833, es decir, un mes antes de que este invadiera Chiapas (Márquez y Reina, 1992).

${ }^{20}$ En la historiografía mexicana sobre la epidemia de cólera de 1833 ha existido cierta confusión en torno a la fecha en la cual el cólera apareció en Chiapas. Cuenya et al. (1992: 43) han indicado que apareció en Tuxtla en julio de 1833 y esta misma fecha ha sido retomada recientemente por Carbajal (2011: 2029). Sin embargo, como lo ha demostrado José López (2010), el cólera no apareció en el estado hasta noviembre de ese año y nosotros tampoco hemos hallado evidencia documental de que la epidemia apareciera antes de esa fecha.

${ }^{21}$ Contreras (2014: 129) afirma que el cólera pasó del pueblo de San Gabriel (hoy El Palmar, en el municipio de Chiapa de Corzo) a Socoltenango. Sin embargo, esta afirmación es totalmente incorrecta, pues ambos pueblos están ubicados en regiones completamente distintas. El error de Contreras se debe a que desconocía la ubicación exacta de San Gabriel cuando redactó su trabajo y lo ubicó equivocamente en la depresión central, cuando en realidad se localiza en el corredor
} 
En las siguientes semanas, el cólera se abatió sobre el pueblo San Felipe, en el valle de Jovel, y sobre Chamula, para finalmente alcanzar la ciudad de San Cristóbal en los últimos días de diciembre de 1833. Desde esta última ciudad y de Chamula, en donde causó 787decesos, siguió hacia los pueblos de las montañas mayas.

A principios del siguiente año, cundió a lo largo de las montañas chamulas. Entre enero y marzo de 1834 Chenalhó, Chalchihuitán, Mitontic, San Andrés, Pantelhó, Santiago, Santa Marta y Magdalenas sufrieron el embate del vibrión. En estos pueblos se registró la mayor mortandad a causa de la epidemia, pues la suma total de difuntos fue de 2156 personas, es decir, poco más de $25 \%$ del total de muertos que dejaría en todo el estado.

Por su parte, en las montañas zendales la epidemia comenzaría a hacer estragos también en enero de 1834. Aunque el recorrido que siguió en esta región no queda muy claro, es posible que desde Amatán, que se vio afectado desde diciembre de 1833, y desde San Cristóbal, el vibrión haya ido avanzando por el resto de los pueblos. Así, Petalcingo y Sabanilla cayeron presas de este mal en los primeros días de enero de 1834, mientras que Tenejapa, Huixtán, Ocosingo, Cancuc, Tenango, Guaquitepec, Yajalón y Tumbalá lo irían haciendo a lo largo de ese mes. Únicamente Moyos resistió su embate durante esos meses, pues en este pueblo se dejó sentir en abril de ese año. En esta región la cifra de muertos ascendió a 1896 personas.

Procedente de San Cristóbal, el cólera hizo su aparición en Teopisca el 11 de enero de 1834, dejando en los siguientes siete meses un total de 83 muertos. Por su parte, las terrazas de Socoltenango, atacadas en ese mismo mes y en febrero, registraron un elevado número de decesos, debido a que en la villa San Bartolomé, bastante populosa, la cifra ascendió a 1099 personas (Barrera, 2017: 144). En este caso, todo indica que las abundantes fuentes de agua de las que disponía este poblado se convirtieron en un medio propicio para la diseminación de la enfermedad (Viqueira, 2009: 13-14; Barrera, 2017: 144).

Luego atacó la ciudad de Comitán y las haciendas que la rodeaban en enero de 1834 y, al paso de los siguientes seis meses, dejó un total de 800 muertos. Luego llegó al pueblo de Zapaluta, en abril de ese año, en donde causó 89 decesos.

Entre la primavera y el verano de 1834 buena parte de los pueblos que se habían mantenido a salvo comenzaron a caer víctimas del contagio. En las mon-

zinacanteco, es decir, a varias decenas de kilómetros de distancia de Socoltenango, pueblo en el cual el cólera entró procedente de los valles de Teopisca en enero de 1834. 
tañas zoques, cuyos pueblos se habían aislado del resto del estado para mantenerse a salvo_como vimos que informó su párroco—, el cólera se abatió sobre la sierra de Tapalapa en abril de ese año y los pueblos de las estribaciones de Chapultenango, mucho más alejados, comenzaron a caer víctimas del mal desde junio.

Entre junio y julio de 1834 el mal atacó algunos pueblos que también parecían haber librado la epidemia. Por ejemplo, en esos meses Aguacatenango, posiblemente Amatenango y Pinola registraron los primeros contagios; además, un rebrote, posiblemente causado por los encharcamientos de la temporada de Iluvias, se registró en Copainalá y Chicoasén, situación que generó alarma entre los habitantes de la villa de Chiapa, quienes le pidieron al gobierno que aislara esos dos pueblos (AHE-UNICACH, Manuscritos, t. 8, leg. 35).

A partir del mes de agosto, las únicas poblaciones que siguieron padeciendo los estragos de la epidemia, hasta donde sabemos, fueron Huixtán, Socoltenango, Moyos y San Cristóbal (Contreras, 2014: 123-124, cuadro 13); en esta última el cólera no desaparecería hasta febrero de 1835, dejando un total de 238 muertos (AHDSC, FD, carp. 3962, exp. 6, f. 1).

En suma, entre los meses de noviembre de 1833 y febrero de 1835 mató a 8445 personas en Chiapas. Esta cifra, pues, representaría 6.8 \% del total de la población que tenía la entidad en 1831.

Como se desprende de los datos anotados, los paisajes humanos más castigados fueron las montañas chamulas y las terrazas de Socoltenango, las cuales habrían perdido $9.5 \%$ de su población cada una, mientras que los llanos de Comitán sufrieron la merma de $8.4 \%$ de sus habitantes.

Las montañas zendales, a pesar de ser el paisaje humano más populoso de Chiapas, perdieron, según nuestros datos, casi $5 \%$ de pobladores a causa del cólera. Sin embargo, la información que poseemos es bastante parcial, pues solo da cuenta de la mortandad en 12 localidades, de tal manera que no tenemos idea de lo sucedido en otras ocho poblaciones, incluyendo algunas bastante importantes en términos demográficos como Tila u Oxchuc.

Otros paisajes que también se vieron afectados de manera considerable fueron los valles de Teopisca y la sierra de Tecpatán, en donde pereció $5.4 \%$ y $6.7 \%$ de población, respectivamente. En los valles de Jiquipilas, Ocozocoautla es el único pueblo del que sabemos el número de muertos; sin embargo, las defunciones registradas en este lugar sumaron $7 \%$ del total de los valles. Asimismo, en el corredor zinacanteco mató a $7 \%$ de su población, aunque no disponemos 
de cifras sobre la mortandad en Zinacantán, que era el pueblo más populoso del conjunto.

En el caso de Chiapa y Tuxtla hemos podido tener noticia de que habría matado a unas 259 personas, es decir, casi 3\% de la población de ambas localidades. Sin embargo, de ser cierto lo que dijeron varios testigos de la época en relación a que el cólera habría cobrado más de 1000 vidas en Tuxtla, este porcentaje podría incrementarse hasta en siete puntos, arrojando un total de muertos de casi $10 \%$ con respecto a la población total; cifra nada descabellada, sobre todo si tomamos en cuenta las características del clima de la zona y el intenso tránsito de personas que en ella se observaba.

Finalmente, las barrancas de Acala, las estribaciones de Chapultenango, la sierra de Tapalapa y el valle de Jovel parecen haber salido mejor librados del embate del cólera, pues en estos paisajes la epidemia no mató a más de $4 \%$ de la población.

Aunque es muy complicado establecer cuáles fueron los factores que facilitaron o frenaron temporalmente el avance del cólera por los pueblos de Chiapas, es muy probable que las condiciones de insalubridad que imperaban en muchas de estas poblaciones hubieran jugado un papel muy importante en su diseminación. Los documentos de la época informan que en las poblaciones del estado lo común era que los espacios públicos, principalmente los mercados, se hallaran llenos de "charcos de sangre [y] otras inmundicias"; cubiertos de suciedad "en las calles, plazas y solares", los cuales llegaban a parecer verdaderos muladares (BMOB, AHC, Salubridad, t. IV, doc. 104, ff. 1-2). Además, las calles de la mayor parte de los pueblos, incluyendo las de San Cristóbal, no se hallaban empedradas (AHDSC, FD, carp. 4386, exp. 6), lo cual facilitaba la acumulación de charcos de agua en donde el vibrión fácilmente sobrevive y a partir de los cuales se propaga (Cuenya, 2006; Alcalá, 2011: 128-132).

A las condiciones de insalubridad se sumaba que el desconocimiento sobre el origen y los factores que facilitaban la propagación de la enfermedad provocó que el gobierno y la sociedad se desgastaran en aplicar medidas que resultaron inútiles para combatirla. Para ejemplificar esto basta indicar que durante la epidemia de 1833 se llegó a achacar el contagio al consumo de ciertos frutos, por lo cual el gobierno prohibió la ingesta de aguacates y duraznos (Claps, 2013: 135-136). Obviamente, la medida no dio ningún resultado. Esto mismo ocasionó que apareciera más de un supuesto remedio consistente, en general, en yerbas 
o platas que crearon gran expectación y esperanza para luego mostrar su total ineficacia. ${ }^{22}$

Ante la imposibilidad de ser detenido y curado, el brote generó tal temor entre la población que los gobiernos municipales, incapaces de frenar la mortandad que dejaba a su paso, buscaron prohibir diversas actividades cotidianas para no atizar la psicosis colectiva. En la villa de San Bartolomé, el ayuntamiento prohibió el toque de campanas de las iglesias a la hora de celebrar las exequias de las víctimas del cólera y la celebración pública de los entierros, al tiempo que mandó a los deudos de las víctimas a no utilizar ropa negra en señal de duelo con la finalidad de "no desalentar los ánimos" en la población (AHDSC, FD, carp. 4078, exp. 1, ff. 1-2).

Paradójicamente, el temor generado entre la población se convirtió en la mejor arma para entorpecer el avance de la enfermedad. Desesperados por evitar su llegada a sus poblados, una parte de los habitantes de Chiapas bloquearon los caminos que los comunicaban con el exterior, de tal forma que en algunos casos se detuvo temporalmente y de forma muy exitosa la entrada y salida de personas. En la parroquia de Tapalapa, como vimos líneas arriba, los indios cerraron los accesos a su pueblo y se mostraron abiertamente hostiles ante quienes se atrevieran a romper el cerco que habían impuesto, situación por la cual su párroco declaró temer por su vida si se aventuraba a entrar en aquellas localidades. Como resultado de lo anterior, si bien la epidemia llegó a los pueblos zoques a finales de 1833 — cuando atacó Quechula_, esa parroquia, junto con la de Chapultenango — ambas ubicadas en dicha región zoque - se mantuvieron a salvo del contagio durante más medio año.

Lo anterior nos haría sugerir, a manera de una hipótesis que tendría que ser corroborada por futuros trabajos que enfoquen su atención en las medidas sanitarias puestas en práctica por los ayuntamientos o los habitantes de los municipios, que en algunos poblados de Chiapas habría ocurrido algo muy similar a lo que Laura Machuca ha demostrado para el caso del pueblo yucateco de Bolonchenticul en donde, frente a la falta de recursos financieros y remedios con los cuales combatir el azote del cólera, la solución que las autoridades municipales hallaron para frenar su avance fue la aplicación de estrictas medidas que con-

\footnotetext{
22 En una circular enviada en febrero de 1834 al ayuntamiento de Chiapa se pidió que una persona acudiera a verificar si era cierta la historia de "una yerba o planta" usada por el caporal de la hacienda de San Nicolás con la que supuestamente se había curado a varias personas enfermas de cólera. Para decepción de todos, el anhelado remedio resultó obviamente un completo fracaso (AHECH-UNICACH, Manuscritos, t. 8, leg. 31).
} 
sistieron en aislar al pueblo de los lugares infestados y solo permitir la entrada de personas de las cuales se tuviera plena certeza de que no estuvieran contagiadas con la bacteria (Machuca, 2006).

Así, un aspecto muy interesante acerca de la forma en la cual el cólera se propagó a lo largo de Chiapas es que muchos pueblos, a pesar de hallarse rodeados de poblaciones infestadas, lograron mantenerse libres de la enfermedad por varios meses, tal como ocurrió con Zapaluta y Pinola que no cayeron presas del embate del cólera hasta marzo y junio de 1834, respectivamente, aunque los pueblos vecinos de Comitán, Socoltenango y San Bartolomé, con los cuales mantenían una intensa red de intercambios, habían sido afectados desde enero de ese año. ¿Se debió lo anterior a que estos pueblos se aislaron exitosamente durante algunos meses?

La efectividad del aislamiento, pues, habría ayudado también a que no cruzara entre 1833 y 1837 la frontera con Guatemala y el Soconusco, regiones que se mantuvieron a salvo de la epidemia hasta este último año. ${ }^{23}$ De ese modo, aunque el gobierno guatemalteco ordenó en 1832 cerrar su frontera con México como medida para evitar que la epidemia se cebara sobre su territorio (El Iris de Chiapas, t. 1, 48), una hipótesis que debería considerarse es que, al igual que en Chiapas, los pueblos fronterizos de Guatemala también pudieron haber cerrado sus accesos de tal forma que ello los puso a salvo de la epidemia que atacaba a sus vecinos mexicanos.

Y tan efectiva pudo resultar esta medida, que para cuando el cólera por fin apareció en Centroamérica en 1837, la única disposición que el gobierno chiapaneco y las municipalidades fronterizas de Chiapas volvieron a poner en práctica fue precisamente la de aislarse de los pueblos que colindaban con la región afectada; dicha disposición resultó efectiva pues no se produjo ningún rebrote de la epidemia en el estado (BMOB, AHC, Salubridad, t. IV, doc. 121).

23 Que el cólera no haya pasado de Chiapas a Guatemala por la frontera comiteca resulta sorprendente a luz de los datos que nos muestran que en esa región se desarrollaban continuos intercambios comerciales entre habitantes de ambos lados. Ejemplo del comercio que existía entre Chiapas y Guatemala es que cuatro meses antes, el gobierno chiapaneco había autorizado al departamento de Comitán la introducción de granos de primera necesidad de Centroamérica. Los encargados de llevarlos hasta Chiapas iban a ser los pueblos denominados chujes, quienes venderían únicamente en las plazas públicas de este departamento su mercancía (El Iris de Chiapas, t. 1, 31: 133). 


\section{Conclusión}

Al igual que ocurrió en el resto de la república mexicana, la población del estado de Chiapas cayó víctima de la epidemia de cólera morbo. A finales de 1833, ante la incapacidad del gobierno de Joaquín Miguel Gutiérrez para mantener al estado aislado de las entidades vecinas afectadas por la epidemia, el vibrión ingresó a Chiapas dejando sus primeros muertos en la ciudad de Tuxtla y los pueblos vecinos.

La difícil situación por la que atravesaba la hacienda pública chiapaneca en esos años, producto de la incapacidad del gobierno para asegurar el ingreso de sus principales rentas, complicó la adopción de las medidas sanitarias que las autoridades habían previsto para proteger a la población del embate del padecimiento. Así, la falta de recursos financieros llevó al gobierno de Gutiérrez a utilizar los caudales que habían pertenecido a la Sociedad de Amigos del País de Chiapas para enfrentar la epidemia, al tiempo que ordenó se utilizaran los fondos de propios y arbitrios de los ayuntamientos para este fin. Además, ordenó la creación de Juntas de Caridad que buscarían apelar a la piedad de los vecinos acaudalados de los municipios de Chiapas para que proporcionaran fondos con los cuales abastecerse de alimentos y medicinas para auxiliar a la población que cayera víctima de la epidemia y amenazó a estos con imponerles préstamos forzosos para este mismo fin.

Aunque el gobierno civil y las Juntas de Caridad recurrieron al auxilio del obispado para que sus ministros colaboraran en el auxilio de la población, con la llegada del cólera, se tornaron aún más complicadas las relaciones entre ministros religiosos y su grey en los curatos indios del obispado, debido a que muchos curas vieron aumentar sus cargas de trabajo, pues su feligresía moribunda solicitó acompañamiento espiritual ante sus inminente muerte. Así, la falta de curas auxiliares hizo declinar los ánimos de los párrocos, sobre todo en aquellos curatos cuyos pueblos, parajes o haciendas anexas se hallaban bastante distantes entre sí.

Además, la epidemia representó una buena oportunidad para que algunos indios pudieran librarse de pagar las raciones a sus párrocos, ocasionando que estos vieran disminuir sus ingresos ya de por sí bastante raquíticos. Estas situaciones llevaron a más de un párroco a abandonar a sus fieles en pleno embate del contagio.

Así, tanto la difícil situación por la que atravesaba el gobierno —el cual se hallaba inmerso en un complicado conflicto político con el clero y sus partidarios- 
como la poca capacidad de los representantes de la Iglesia católica en varios de los pueblos del estado para atender a su congregación enferma, se sumaron a que muchas de las medidas que fueron diseñadas para enfrentar al epidemia no se llevaran a la práctica de forma adecuada. Un ejemplo de ello fue la apertura de cementerios civiles para enterrar a las víctimas. Así, ante la falta de vigilancia, muchas personas siguieron siendo enterradas en las iglesias o en montes o campos, en donde quedaron fuera de la fiscalización de las autoridades civiles y eclesiásticas.

Esto último, a más de mostrarnos diversos aspectos de la vida social de Chiapas durante los años posteriores a la independencia, que dificultaban el afianzamiento del control gubernamental sobre la población, debe importarnos a los historiadores pues contribuyó a engrosar el subregistro de defunciones causadas por el cólera.

Hemos creído importante mostrar que, aunque disponemos de fuentes que nos permiten conocer el número de muertos por la epidemia, estas nos brindan una visión muy limitada de la magnitud de su impacto demográfico en Chiapas y que solamente conociendo las causas y la forma en que se materializó este subregistro podremos utilizarlas con mayor precisión. Según nuestros cálculos, acabó con por lo menos 6.8\% de los 122914 habitantes del estado en 1831.

No sería hasta 1850, y sobre todo en 1882 (Zavala, 2007 y Barrera, 2017: 130; 146; 171), cuando dos nuevos embates de cólera afectarían las vidas de los habitantes de Chiapas. Sin embargo, contar esas historias ya no es materia de este trabajo.

\section{Archivos}

Archivo Histórico Diocesano de San Cristóbal (AHDSC)

Fondo Diocesano (FD)

Fondo Parroquial (FP)

Archivo Histórico del Estado de Chiapas (AHE-UNICACH)

Biblioteca Manuel Orozco y Berra (BMOB)

Archivo Histórico de Chiapas (AHC) 


\section{Fuentes hemerográficas}

El Iris de Chiapas, t. 1., núm. 27, San Cristóbal, 18 de marzo de 1833.

El Iris de Chiapas, t.1, núm. 31, San Cristóbal, 15 de abril de 1833.

El Iris de Chiapas, t. 2, núm. 8, San Cristóbal, 25 de noviembre de 1833.

\section{Fuentes de consulta}

Alcalá, Carlos (2012), "Cólera, mortalidad y propagación en la península de Yucatán, 1833-1834", en Letras Históricas, 7, pp. 115-141.

Alcalá, Carlos y Alicia Contreras (eds.) (2014), Cólera y población. Estudios sobre México y Cuba, 1833-1854, México, El Colegio de Michoacán.

Ariès, Philippe(1984), El hombre ante la muerte, Madrid, Taurus.

Barrera, Óscar (2017), Las Terrazas de los Altos. Lengua, tierra y población en la depresión central de Chiapas, tesis para obtener el grado de doctor en historia, Centro de Estudios Históricos-El Colegio de México, México.

Carbajal, David (2011), "La epidemia de cólera de 1833 en el obispado de Guadalajara. Rutas decontagio y mortalidad", en Historia mexicana, LX(4), pp. 2025-2067.

Claps, María Eugenia (2011), "El Iris de Chiapas y los ayuntamientos", en R. Ortiz y C. del Carpio (coords.), Seis ensayos sobre historia de Centroamérica, Tuxtla Gutiérrez, Universidad de Ciencias y Artes de Chiapas, pp. 125-140.

Contreras, Julio (2014), "El cólera morbus de 1833-1834 en el estado de Chiapas", en C. Alcalá y A. Contreras (editores), Cólera y población. Estudios sobre México y Cuba, 1833-1854, México, El Colegio de Michoacán, pp. 113-143.

Cuenya, Miguel Ángel, et, al (1992), El cólera de 1833: una nueva patología en México: causas y efectos, México, Instituto Nacional de Antropología e Historia.

Cuenya, Miguel Ángel (2006), "El cólera morbus en una ciudad de la provincia mexicana. Puebla de los Ángeles en 1833", en Mundo Nuevo Nuevos Mundos, disponible en: $<$ https://nuevomundo.revues.org/3103 $>$ (consulta:08/06/2016].

Flores, Eduardo (1978), La catedral de San Cristóbal de Las Casas, 1528-1978, México, Universidad Autónoma de Chiapas.

Gutiérrez, Sergio Nicolás (2013), "De la intendencia de Ciudad Real al estado federal chiapaneco, 1786-1835", en S. N. Gutiérrez y M. E. Claps Arenas (coords.), Formación y gestación del estado en Chiapas. Algunas aproximaciones históricas, México, Universidad de Ciencias y Artes de Chiapas, pp. 19-41.

López Flores, José Airam (2010), El cólera morbos en Chiapas. Primera mitad del siglo $X I X$, tesis para obtener el grado de licenciado en historia, Universidad Autónoma de Chiapas, San Cristóbal de Las Casas.

Machuca Laura (2006), "Control y poder en época de enfermedades. El cólera morbus de 1833 y el pueblo de Bolonchenticul, península de Yucatán, México", en Rev Biomed, 17, pp. 140-145.

Márquez, Lourdes y Leticia Reina (1992), "El cólera en Oaxaca en el siglo XIX", Cuadernos Ciencias Sociales, t. I, pp. 71-98. 
Márquez, Lourdes (1994), La desigualdad ante la muerte en la Ciudad de México. El tifo y el cólera, México, Siglo XXI.

Ortiz, Rocío (2003), Pueblos indios, Iglesia católica y élites políticas en Chiapas (18211914). Una perspectiva comparativa, Tuxtla Gutiérrez, Consejo Estatal para las Culturas y las Artes / El Colegio de Michoacán.

Ortiz, Rocío (2005), "Indios principales, ayuntamientos indios y representantes de la iglesia católica en la tierras altas de Chiapas. 1824-1869", en D. Palomo y M. Olivera (coords.) Chiapas: de la Independencia a la Revolución, México, Centro de Estudios Superiores en Antropología Social / Consejo de Ciencia y Tecnología del Estado de Chiapas, pp. 141-162.

Obara, Tadashi y Juan Pedro Viqueira (2017), El arte de contar tributarios. Provincia de Chiapas, 1528-1821, México, El Colegio de México.

Ruz, Mario Humberto (1992), Savia india, floración ladina. Apuntes para el estudio de la fincas comitecas (siglos XVIII y XIX), México, Consejo Nacional para la Cultura y las Artes.

Torres, Amanda (2014), "Los hombres de bien" en Chiapas. Un estudio de la elite política chiapaneca, 1825-1835, tesis para obtener el grado de doctora en historia, Universidad Autónoma Metropolitana-Unidad Iztapalapa, México.

Viqueira, Juan Pedro (2007), "Amar a Dios en tierra de indios: la vida cotidiana de los párrocos de San Andrés (Larráinzar), Chiapas, 1774-1914", en P. Gonzalbo y M. Bazant (coords.), Tradiciones y conflictos, historias de la vida cotidiana en México e Hispanoamérica, México, El Colegio de México / El Colegio Mexiquense, pp. 179-209.

Viqueira, Juan Pedro (2009), "Cuando no florecen las ciudades: la urbanización tardía e insuficiente de Chiapas", en C. Lira y A. Rodríguez (coords.), Ciudades mexicanas del siglo XX. Siete estudios históricos, México, El Colegio de México / Universidad Autónoma Metropolitana / Consejo Nacional de Ciencia y Tecnología, pp. 221-270.

Viqueira, Juan Pedro (2016), "Memorias históricas e identidades contrapuestas: el caso de la rebelión de 1712 en Chiapas", Revista Mundaú, 1,pp. 12-37.

Zavala, María del Carmen (2007), "El cólera en Michoacán y la federalización de las políticas sanitarias en el siglo XIX", Tzintzun. Revista de Estudios Históricos, 46, julio-diciembre, pp. 39-88. 
Apéndice I. Defunciones por cólera en Chiapas, 1833-1835

\begin{tabular}{|c|c|c|c|}
\hline Localidad & Defunciones & $\begin{array}{l}\text { Fecha de inicio de la } \\
\text { epidemia }\end{array}$ & Fuente \\
\hline Totolapa & 45 & Abril de 1834 & AHDSC, FD, carp. 322, exp. 3 \\
\hline San Lucas & 38 & Abril de 1834 & AHDSC, FD, carp. 322, exp. 3 \\
\hline Chiapa & 204 & Noviembre de 1833 & AHDSC, FD, carp. 199, exp.20 \\
\hline Tuxtla & 55 & 8 de noviembre de 1833 & Contreras, 2014: 123-124, cuadro 13 \\
\hline San Gabriel & 42 & Noviembre de 1833 & Contreras, 2014: 123-124, cuadro 13 \\
\hline Soyaló & 32 & Diciembre de 1833 & Contreras, 2014: 123-124, cuadro 13 \\
\hline Chapultenango & 108 & Junio de 1834 & AHDSC, FD carp. 1355, exp. 2 \\
\hline Nicapa & 60 & Junio de 1834 & AHDSC, FD carp. 1355, exp. 2 \\
\hline Sunuapa & 46 & Junio de 1834 & AHDSC, FD carp. 1355, exp. 2 \\
\hline Tectuapán & 41 & Junio de 1834 & AHDSC, FD carp. 1355, exp. 2 \\
\hline $\begin{array}{l}\text { Parroquia de } \\
\text { Comitán }\end{array}$ & 800 & Enero de 1834 & AHDSC, FD carp. 2619, exp. 3 \\
\hline Zapaluta & 89 & Marzo de 1834 & Contreras, 2014: 123-124, cuadro 13 \\
\hline $\begin{array}{l}\text { San Juan } \\
\text { Chamula }\end{array}$ & 787 & 22 de diciembre de 1833 & AHDSC, FD, carp. 513, exp. 4 \\
\hline $\begin{array}{l}\text { San Pedro } \\
\text { Chenalhó }\end{array}$ & 378 & Enero de 1834 & AHDSC, FD carp. 3228, exp. 4 \\
\hline $\begin{array}{l}\text { San Pablo } \\
\text { Chalchihuitán }\end{array}$ & 202 & Enero de 1834 & AHDSC, FD carp. 3228, exp. 4 \\
\hline $\begin{array}{l}\text { San Miguel } \\
\text { Mitontic }\end{array}$ & 88 & Enero de 1834 & AHDSC, FD carp. 3228 , exp. 4 \\
\hline San Andrés & 212 & Enero de 1834 & AHDSC, FD, carp. 769, exp. 4 \\
\hline Santa Magdalena & 132 & Primera mitad de 1834 & AHDSC, FD, carp. 769, exp. 4 \\
\hline Santa María & 74 & Primera mitad de 1834 & AHDSC, FD, carp. 769, exp. 4 \\
\hline Santiago & 102 & Marzo de 1834 & AHDSC, FD, carp. 769, exp. 4 \\
\hline $\begin{array}{l}\text { Santa Catarina } \\
\text { Pantelhó }\end{array}$ & 181 & Enero de 1834 & AHDSC, FD, carp. 668, exp. 3 \\
\hline Tumbalá & 155 & Finales de enero de 1834 & AHDSC, FD carp. 1856, exp. 4 \\
\hline Sabana de Tulijá & 152 & Finales de enero de 1834 & AHDSC, FD carp. 1756, exp. 1 \\
\hline Tenejapa & 471 & $\mathrm{Nd}$ & AHDSC, FD, carp. 3158, exp. 3 \\
\hline Huixtán & 224 & $\mathrm{Nd}$ & AHDSC, FD, carp. 3158 , exp. 3 \\
\hline Yajalón & 69 & Enero de 1834 & AHDSC, FD, carp. 3209, exp. 4, f. 1v \\
\hline Sabanilla & 108 & 7 de enero de 1834 & Contreras, 2014: 123-124, cuadro 13 \\
\hline Guaquitepec & 74 & Enero de 1834 & Contreras, 2014: 123-124, cuadro 13 \\
\hline Moyos & 94 & Abril de 1834 & Contreras, 2014: 123-124, cuadro 13 \\
\hline Cancuc & 166 & $\mathrm{Nd}$ & AHDSC, FD, carp. 5710, exp. 20 \\
\hline Tenango & 67 & $\mathrm{Nd}$ & AHDSC, FD, carp. 5710, exp. 20 \\
\hline Petalcingo & $\mathrm{Nd}$ & 1 de enero de 1834 & $\begin{array}{l}\text { AHDSC, FP, Defunciones, caja } 303 \\
\text { Libro 6, ff. 88-107. }\end{array}$ \\
\hline
\end{tabular}




\begin{tabular}{|l|c|l|l|}
\hline Ocosingo & 316 & Nd & AHDSC, FD, exp. 3600, exp. 46 \\
\hline Tapilula & 56 & Abril de 1834 & AHDSC, FD, carp. 1528, exp. 1 \\
\hline Comistahuacán & 63 & Semana Santa de 1834 & AHDSC, FD, carp. 1528, exp. 1 \\
\hline Ixhuatán & 28 & Semana Santa de 1834 & AHDSC, FD, carp. 1528, exp. 1 \\
\hline Amatán & 41 & Diciembre de 1833 & Contreras, 2014: 123-124, cuadro 13 \\
\hline Tecpatán & 165 & Enero de 1834 & Contreras, 2014: 123-124, cuadro 13 \\
\hline Quechula & 130 & 8 de noviembre de 1833 & Contreras, 2014: 123-124, cuadro 13 \\
\hline San Bartolomé & 1099 & Enero de 1834 & AHDSC, FD carp. 395, exp. 12 \\
\hline Socoltenango & 184 & Febrero de 1834 & Contreras, 2014: 123-124, cuadro 13 \\
\hline San Cristóbal & 237 & 29 de diciembre de 1833 & AHDSC, FD, carp. 3962, exp. 6, f. 1 \\
\hline San Felipe & 30 & 3 de diciembre de 1833 & AHDSC, FD, 4930, exp. 2 \\
\hline Ocozocoautla & 210 & 9 de noviembre de 1833 & AHDSC, FD, carp. 1201, exp. 1 \\
\hline Teopisca & 83 & Enero de 1834 & AHDSC, FD, carp. 5673, exp. 11 \\
\hline Pinola & 55 & Junio de 1834 & Contreras, 2014: 123-124, cuadro 13 \\
\hline Aguacatenango & 28 & Julio de 1834 & AHDSC, FD, carp. 5673, exp. 11 \\
\hline Tonalá & 424 & Enero de 1834 & Contreras, 2014: 123-124, cuadro 13 \\
\hline Chicoasén & $\mathrm{Nd}$ & Primavera 1834 & AHC, Manuscritos,t. 8, leg. 35 \\
\hline Copainalá & $\mathrm{Nd}$ & Primavera 1834 & AHC, Manuscritos,t. 8, leg. 35 \\
\hline Total & 8445 & & \\
\hline & & & \\
\hline
\end{tabular}

Apéndice II. Defunciones por cólera agrupadas por paisajes humanos

\begin{tabular}{|c|c|c|c|}
\hline Paisaje humano* & $\begin{array}{l}\text { Número de } \\
\text { muertos }\end{array}$ & $\begin{array}{l}\text { Número de habitantes } \\
\text { registrados en } \\
\text { padrones de 1824, } \\
\text { 1828-1831** }\end{array}$ & $\begin{array}{l}\text { Porcentaje de } \\
\text { muertos con } \\
\text { respecto a la } \\
\text { población total }\end{array}$ \\
\hline Barrancas de Acala & 83 & 2806 & $2.90 \%$ \\
\hline Chiapa y Cuenca de Tuxtla & 259 & 8724 & $2.90 \%$ \\
\hline Estribaciones de Chapultenango*** & 255 & 6488 & $3.90 \%$ \\
\hline Llanos de Comitán & 889 & 10553 & $8.40 \%$ \\
\hline Montañas Chamulas & 2156 & 22609 & $9.50 \%$ \\
\hline Montañas Zendales ${ }^{\star \star \star *}$ & 1896 & 38881 & $4.80 \%$ \\
\hline Sierra de Tapalapa & 147 & 3012 & $4.80 \%$ \\
\hline 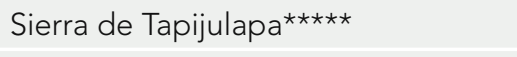 & 41 & 467 & $8.70 \%$ \\
\hline Sierra de Tecpatán & 295 & 4384 & $6.70 \%$ \\
\hline Terrazas de Socoltenango & 1338 & 14018 & $9.50 \%$ \\
\hline Valle de Jovel & 267 & 7740 & $3.40 \%$ \\
\hline Valles de Jiquipilas & 210 & 2996 & $7 \%$ \\
\hline Corredor Zinacanteco & 74 & 1040 & $7.10 \%$ \\
\hline Valles de Teopisca & 111 & 2033 & $5.40 \%$ \\
\hline 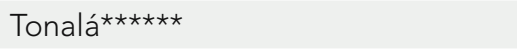 & 424 & 4251 & $9.90 \%$ \\
\hline
\end{tabular}


Fuente: Apéndice I; BMOB, AHC, Memorias, t. III, doc. 52 y Obara y Viqueira, 2017, Tributarios de la provincia de Chiapa, 1595-1818.

* La agrupación por paisajes humanos se ha hecho con base en Obara y Viqueira (2017, mapa 10). Por falta de datos no hemos incluido a los valles de Jitotol en este cuadro.

** Advertimos al lector que no intente sumar el total de población de cada paisaje humano para obtener el total de población de Chiapas. Esto se debe a que lo que hemos querido hacer con este cuadro es mostrar únicamente el posible impacto relativo de la epidemia por paisaje humano, para lo cual hemos procedido de forma muy arbitraria empleando cifras de años diversos con el fin de completar una idea aproximada del tamaño de la población por paisaje. Así, los totales de cada uno de estos no tienen ninguna relación entre sí y, por consiguiente, no expresan el número total de habitantes de Chiapas en algún momento dado.

*** Por razones que desconocemos, las autoridades de Chiapas no habían sido capaces, desde la consumación de la independencia, de conocer el número de habitantes de varios pueblos de las estribaciones de Chapultenango, entre ellos Ixtapangajoya, Nicapa, Sunuapa, Ostuacán y Sayula, por tanto la población total de este paisaje aparece disminuida.

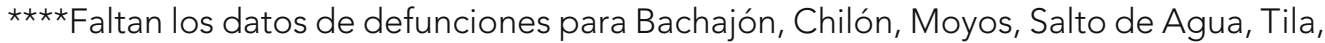
Oxchuc, Sitalá y Sibacá.

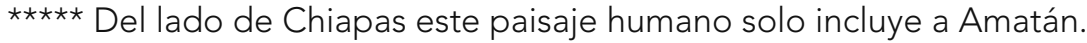

$\star \star \star \star \star \star$ Solo se presentan los datos de Tonalá. 